\title{
Linux versus Microsoft: as novas tendências no mercado de sistemas operacionais
}

\author{
Linux versus Microsoft: the new tendencies \\ in the operating systems' market
}

Antonio Teodoro Ribeiro GUIMARÃES 1

R E S U M O

O objetivo deste artigo foi contar um pouco da história do desenvolvimento da indústria mais competitiva da segunda metade do século passado: os computadores e seus sistemas operacionais e aplicativos, e de entender a atuação da Microsoft e de como ela influenciou de maneira importante o desenrolar dos acontecimentos, tornando-se esse "gigante do software", com fortes tendências monopolistas, que, em sua trajetória, derrotou todos os concorrentes que apareceram em seu caminho, conseguindo com isso colecionar inimigos poderosos. Nesse cenário de inconformismo, surge o Linux, software livre apoiado por grandes empresas, entre as quais estão algumas antigas concorrentes derrotadas pela Microsoft. O Linux vem ocupando enorme espaço no mundo corporativo, estando já quase maduro tecnologicamente para marcar sua presença no mercado, em arquitetura Intel, e se prepara para investir contra a reserva de mercado do Windows, em plataforma baixa, e invadir o mundo dos computadores pessoais. Chegou afinal um concorrente de peso para enfrentar o império?

Palavras-chave: código aberto, Microsoft, Linux.

\section{A B S T R A C T}

The objective of this article is to tell a little of the development history of the most competitive industry on the second half of last century, the computers and their

\footnotetext{
1 Docente, Curso Administração de Empresas, Faculdade Fleming. Rua Maria Umbelina Couto, 58, Guanabara, 13090-110, Campinas, SP, Brasil.E-mail: <teodoroguimaraes@uol.com.br>.

Recebido em 7/6/2004 e aceito para publicação em 15/2/2005.
} 
operating systems and applications. We'll cast some light on the performance of Microsoft and on how they have influenced in a significant way the unrolling of events, thus becoming the "software's giant" it did. Taking a monopolist position, Microsoft caused serious damages to its several market competitors, having in turn collected powerful enemies with a strong disposition to ask much more for their defeats. In the ensuing uncomfortable scenario, Linux, an independent software emerges supported by big companies, including earlier Microsoft opponents. Since then, Linux has been occupying a quite large space in the corporate world, being almost ripe, technologically, to underscore its presence in the market, in Intel architecture. Linux is also getting prepared, on low platform, to invest against the locked market of Windows, and to invade the personal computers world. Has a heavy competitor arrived, at last, to confront the empire?

Key words: open source, Microsoft, Linux.

\section{N T R O D U Ç Ã O}

A Microsoft, desde que vendeu o que não tinha à IBM (ROHM, 2001), em 1981, sempre se caracterizou pela extrema agressividade de seu fundador, Bill Gates, ao buscar o sucesso, e, mais que isso, num país que se orgulha de ser o campeão na luta a favor da livre-concorrência, ter construído e até hoje administrar um dos mais sólidos monopólios do mundo moderno, que vem ganhando nos tribunais a condição de sustentação legal de seu negócio.

Para a construção do cenário de nosso estudo, optamos por descrever, de maneira breve, enfatizando, entretanto, os aspectos mais importantes, o desenvolvimento da indústria da informática, desde as primeiras tentativas humanas de processar informações, até nossos dias.

Esse cenário é o palco de um novo momento histórico, onde surge um movimento que envolve grandes empresas, pesquisadores e programadores independentes, além de uma miríade de empresas de consultoria, todos unidos num só projeto, que é o de dar consistência, funcionalidade, segurança e confiabilidade a um novo sistema operacional concorrente do Windows, chamado Linux, que não tem uma empresa proprietária.

Com essas informações em mente, começamos a pesquisar, alinhar cronologica- mente os fatos (sempre que possível) e analisar o comportamento competitivo das empresas que participaram da história do desenvolvimento do computador, desde as primeiras tentativas de processamento de dados, até a sua transformação nesse fantástico instrumento de apoio funcional dos nossos dias, desta nova e "ciberneticamente dependente" civilização que estamos construindo.

Além disto, amparados pela reflexão sobre estudos muito recentes publicados em revistas especializadas, que analisam $o$ atual estágio de desenvolvimento do Linux, e guiados pelo desejo de compreender as ações estratégicas atuais da Microsoft, imaginamos dois cenários (no sentido estrito de scennary) para onde poderão convergir os resultados dessa disputa.

\section{Os primeiros tempos - a ciência se desenvolve}

O desenvolvimento da informática, desde o seu início, nunca foi planejado, estruturado, ou seguiu qualquer princípio lógico. Foi, na verdade, uma sucessão de estabilizações provisórias, de reaproveitamentos de idéias, às vezes abandonadas, e de encadeamentos desordenados de conceitos e teorias ao longo do tempo. Também não foi a realização de um sonho, tenha sido ele de Leibniz, Babbage, 
Hollerith, Jobs, Dell ou mesmo Gates. Foi maior que um sonho. Nunca existiram limites.

Existem correntes de pensadores que preferem ligar a história do tratamento da informação às marcas em ossos e pedras da pré-história. Outras correntes, aos ábacos sumérios e chineses. Isso, na verdade, não é tão relevante, pois, o que realmente importa é a sua ligação com a história econômica dos povos e do pensamento lógico do homem, em todos os tempos de vida inteligente no planeta. $O$ avanço da vida civilizada implicou, por sua vez, no avanço do cálculo, e as soluções foram surgindo, cada vez mais complexas, à medida que as ciências iam elevando o nível do conhecimento.

O surgimento do capitalismo mercantil na Europa pré-renascentista exigiu controles numéricos mais aperfeiçoados, o que propiciou o crescimento das universidades, impulsionando, por sua vez, a ciência e a pesquisa, criando as condições para a passagem para o capitalismo pré-industrial. Isto levou ao desenvolvimento da fundamentação teórica de recursos matemáticos, que trouxeram as primeiras máquinas de processamento de cálculos. John Napier (1550-1617), matemático escocês, inventa os logaritmos, e tabelas de multiplicação gravadas em cilindros de madeira. Para facilitar o desenvolvimento dos complexos cálculos dos logaritmos, William Oughtred (1574-1660), cria a primeira régua de cálculo da história. O astrônomo alemão Wilhelm Schickard (1592-1635), criou a primeira máquina de calcular, que se perdeu durante a guerra dos trinta anos (1618-1648), e pouco se sabe dela. Em 1642, Blaise Pascal (1623-1662), matemático e filósofo francês, inventou um mecanismo que fazia adição e subtração de números. Gottfried Wilhelm Leibniz (1646-1716), alemão, aperfeiçoa o invento, introduzindo o chamado "cilindro de Leibniz". Também projetou uma máquina que fazia as quatro operações, que não se sabe ao certo se chegou a ser construída.
Na revolução industrial do século XVIII surgem os fundamentos da economia de escala, e a conseqüente necessidade de controles e cálculos cada vez mais sofisticados, sendo que, nesse período, aparecem inúmeros dispositivos de calcular, ainda de baixa precisão e pouca funcionalidade. Uma exceção foi a criação de Joseph-Marie Jacquard (1752-1834), inventor francês, que construiu um tear mecânico, onde, graças a um dispositivo de processamento através de pinos, é "lida" uma seqüência de cartões perfurados, possibilitando que a máquina reproduza infinitamente os padrões de cores e tramas pré-determinados naqueles cartões. Charles Babbage (1792-1871), matemático inglês, membro da Royal Society, professor em Cambridge, que já havia projetado uma máquina que deveria calcular Equações Diferenciais, aproveitando-se dos conceitos de Jacquard, começa a desenvolver o projeto de uma máquina que seria capaz de efetuar quaisquer cálculos, a partir de instruções "lidas" em cartões perfurados. A partir de 1834, e até o final de sua vida, Babbage dedicou-se ao projeto, que denominou "Analytical Engine". A máquina não chegou a ser construída, mas um programa de demonstração é escrito para ela por Lady Lovelace (Ada Augusta Byron), a "primeira programadora" da história, que com ele calculava séries matemáticas de números.

Por razões de desenvolvimento tecnológico e conhecimento de resistência de materiais, os primeiros equipamentos de calcular realmente confiáveis somente surgiram em meados do século XIX. Em 1866, William S. Burroughs funda a companhia que leva seu nome e começa a fabricar em série máquinas de somar mecânicas, que sobreviveram por mais de 100 anos, até que as calculadoras eletrônicas decretassem a sua morte. Em 1847, George Boole (1815-1864), matemático inglês, desenvolve os raciocínios lógico-matemáticos condicionais que são chamados de "álgebra booleana". Em 1900, o dinamarquês Valdemar Poulsen (1869-1942) desenvolve o fundamento da memória magnética, 
fazendo os primeiros registros de dados em um fio de arame. Em 1906, Lee De Forest, norte-americano, inventa a válvula, e, em 1938, Claude Shannon demonstra que conjuntos de válvulas podem realizar operações lógicas pré-determinadas.

O estatístico norte-americano Hermann Hollerith (1860-1929), funcionário do Censo americano, inconformado com a demora do processamento manual dos dados do censo de 1880, que levou 7 anos para ficar pronto, e baseando-se nos fundamentos desenvolvidos por Babbage e seus cartões perfurados, construiu uma máquina para fazer o processamento dos dados do censo de 1890. O tempo do trabalho caiu para 2 anos, e o sucesso foi tão grande que Hollerith fundou sua própria empresa para fabricá-la, que chamou-se Tabulating Machine Company. Anos mais tarde, já vitoriosa, com máquinas de processamento de censo vendidas para quase todos os países do mundo, alterou seu nome para Industrial Business Machines (IBM), pioneira na utilização de eletricidade para a perfuração e leitura de cartões.

\section{O setor empresarial se interessa pelos computadores}

O mundo, tecnologicamente, estava pronto para o processamento eletrônico de dados. Mas o volume de recursos necessários para o desenvolvimento dos equipamentos era tão alto que nem mesmo os governos estavam dispostos a investir. Apenas quando o ambiente internacional começa a ficar tenso, com os fatos políticos que trariam a 2 $2^{-a}$ Guerra Mundial, é que os comandos militares dos países envolvidos envidam esforços para desenvolver o processamento eletrônico de dados.

Nos Estados Unidos, foram dois os projetos militares para o desenvolvimento de computadores: o projeto do exército, de 1943, que previa a fabricação de um equipamento para cálculos balísticos, tendo sido construído por George Stiblitz. O projeto da marinha era mais antigo, pois desde 1937, em segredo, esta vinha, em parceria com a Universidade de Harvard, construindo o Harvard Mark I, que é entregue em 1943, já obsoleto no próprio lançamento. Um segundo modelo vinha sendo desenvolvido, desde 1939, por Howard Hathaway Aiken, e o sucesso de seu protótipo animou a IBM a associar-se ao projeto e a investir em seu desenvolvimento, naturalmente não mais com objetivos militares. O Harvard Mark II, com relês eletro-mecânicos, é lançado em 1945.

Até 1944, as instruções dirigidas ao computador eram armazenadas externamente à máquina (fitas perfuradas, cartões perfurados, ou fios). Em 1945, John von Neumann (1903-1957), introduz o armazenamento codificado de instruções na memória do computador. A idéia é posta em pratica no Electronic Discrete Variable Computer(EDVAC), construído pela Universidade da Pensilvânia (1946) com os engenheiros John W. Mauchly e John Prosper Eckert. Este é o primeiro computador a trabalhar com números em base binária, e também com palavras, chegando a colocar uma lista de nomes em ordem alfabética.

No modelo seguinte, de 1946, a Universidade da Pensilvânia substituiu os relês eletro-mecânicos por válvulas eletrônicas. É o Electronic Numerical Integrator and Computer (ENIAC), primeiro computador eletrônico programável, um monstro de 30 toneladas extremamente rápido. Nele trabalham, além de Mauchly e Eckert, nomes como Alan Turing e John von Neumann. Em 1950, Mauchly e Eckert montam o próprio negócio para fabricar uma versão comercial do ENIAC: a Eckerte Mauchly Computer Corporation. Grace Hopper desenvolve programas de uso comercial para a máquina. É ela quem cria a primeira linguagem de programação, junto com o compilador necessário para traduzi-lo em linguagem de máquina, o AO. O projeto da empresa é chamado Universal 
Automatic Computer(UNIVAC). A introdução das válvulas eletrônicas permite que tarefas que até então demoravam um ano para serem concluídas, demorassem apenas um dia, e é o primeiro a utilizar fitas magnéticas para alimentação e armazenamento de dados. A jovem empresa é adquirida em 1951 pela Remington Rand.

A IBM não hesitou em vencer sua concorrente quando a ocasião assim o permitiu. Como, àquela época, os clientes para computadores eram os governos e universidades, e quem tinha tradição nesse tipo de equipamento sofisticado, caro e praticamente "sob medida", era a IBM, a questão foi decidida por um maciço emprego de recursos por parte dela. O que estava em jogo? O controle do desenvolvimento do produto mais notável do século XX.

Depois da vitória sobre a Rand, a IBM consolidou sua posição, e apesar de algumas empresas terem entrado no negócio de computadores, como a Burroughs, a NCR, e outras, a IBM continuou dominando o mercado, alcançando a marca dos $60 \%$ a $70 \%$ do total de máquinas vendidas (RIES; TROUT, 1989). A indústria de computadores passou a ser conhecida como "Branca de Neve e os sete anões".

Em 1969, a Bell Laboratories, que posteriormente foi incorporada pela AT\&T, desenvolveu o sistema operacional Unix, que passou a ser utilizado pelos mainframe, em razão de sua eficiência e estabilidade. Nesse mesmo ano, numa decisão estratégica, com a intenção de aumentar os programas aplicativos disponíveis para seus computadores, a IBM "abriu" a arquitetura de seus hardware e software, permitindo uma revolução entre os criadores de software. Apesar de inicialmente ter sido um sucesso, os anos que se seguiram mostraram o tamanho do erro dessa decisão, pois também trouxe uma revolução no hardware, com o surgimento dos equipamentos inteiramente copiados, na década de 70 .

A primeira derrota séria sofrida pela IBM veio no início da década de 70 , pela DEC e seus minicomputadores, que em 1965 já tinha apresentado o PDP-8, abrindo caminho para as mini-plataformas. Aí a IBM cometeu o primeiro de uma série de enganos. Não reagiu ao ataque da DEC, só entrando em 1976 no mercado com o seu Série 1. Mas nem mesmo a IBM pode jogar fora 11 anos e imaginar que ainda pode sair-se bem (RIES; TROUT, 1989). Nos anos subseqüentes, ela jamais ultrapassou $10 \%$ de participação no mercado, enquanto a DEC, mesmo com a entrada da concorrência, sempre esteve acima de $40 \%$ de participação no mercado de minicomputadores, enquanto ele existiu.

\section{Os microcomputadores}

A década de 70 traz a tecnologia Large Scale Integration (LSI), que concentra milhares de transistores em uma única pastilha de silício. Rapidamente passam a ser dezenas, e logo centenas de milhares (tecnologia Very Large Scale Integration (VLSI)) - A fabricação desses chips em escala industrial, trouxe em seu bojo qualidade com baixo custo, o que permitiu que fossem incorporados a outros equipamentos, levando o controle computadorizado para máquinas de lavar, fomos de microondas, televisores, som, vídeo, automóveis, máquinas industriais e outros infinitos equipamentos e produtos, numa verdadeira revolução eletrônica.

É nesse contexto que a Unidade Central de Processamento (CPU) dos computadores passa a estar contida num único chip- o microprocessador. O primeiro é o da Integrated Electronics Corporation (INTEL), fundada em 1968 por Gordon Moore e Robert Noyce. Em 1972 essa empresa lança o INTEL 8008, uma nova geração de microprocessadores de 8 bits, com maior capacidade e confiabilidade, e alguns entusias-tas amadores começam a construir seus próprios computadores baseando-se no novo chip. Uma versão melhorada é apresentada em 1974, o Intel 8080. A esta altura surgem os 
concorrentes para a Intel. O principal foi o chip 6800 , da Motorola, que era semelhante ao 8080 em termos de hardware, mas utilizava instruções diferentes para operar, iniciando-se os problemas de compatibilidade de software entre máquinas.

Em 1975, dois estudantes de Harvard, William Henry Gates III (Bill Gates) e Paul Allen criam a Microsoft Corporation para desenvolver softwares. O primeiro produto é um interpretador Basic, desenvolvido num DEC PDP-10, vendido para a MITS, e que passa a fazer parte do kit do micro ALTAIR, que era vendido pelo correio para ser montado em casa, e foi o primeiro microcomputador norte-americano.

Em 1976, dois jovens engenheiros, Steve Jobs e S. Wosniak, venderam todo o seu patrimônio pessoal (uma Kombi e uma calculadora eletrônica) e, numa garagem emprestada, iniciaram a grande revolução dos microcomputadores, com a construção do Apple I. No ano seguinte, lançam o primeiro microcomputador que foi aceito pelo mercado comercial, o desktop Apple II, que, além do Basic, incluía uma planilha de cálculo chamada VisiCalc. É o primeiro micro a ter unidade de disco flexível.

Em 1978 a Intel anuncia o chip 8088, com capacidade de processamento semelhante ao mainframe IBM 360/50. O micro doméstico, neste momento já é uma realidade. Não é só a indústria do hardware que se desenvolve. Junto com ela vêm os periféricos e os softwares. A partir de 1980, os microcomputadores vão se tornando gradualmente mais e mais baratos e confiáveis, e mais acessíveis ao grande público. Sua popularidade chegou ao ponto de, em 1982, a revista norte-americana TIME eleger 0 microcomputador como o "Homem do Ano" (RAPP; COLLINS, 1994).

Em 1980 a DEC era a maior fabricante do mundo de computadores pequenos. Em 1981 a IBM lançou o PC. Alguns anos depois, a DEC estava fora do mercado. Por alguns poucos milhares de dólares, um microcomputador fazia a maioria dos trabalhos para os quais antes era necessário um mainframe de mais de um milhão de dólares (RIES; TROUT, 1989).

Em 1981, a sorte ajudou a Microsoft. Mary Gates, mãe de Bill, havia trabalhado na United Way com John Opel, quem agora estava presidindo a IBM, e andava à procura de um sistema operacional para o microcomputador que a empresa iria lançar. Gates não tinha um sistema operacional, mas mesmo assim assinou um contrato com a IBM para entregá-lo em poucos meses. Paul Allen comprou então, da Seattle Computer Products, um sistema chamado Q-DOS, que foi adaptado e licenciado para a IBM, ficando os direitos da patente para a Microsoft (ROHM, 2001).

Essa liberação dos direitos de patente mostrou-se equivocada ao longo do tempo, pois os executivos da Big Blue, ao acharem que o valor estava na máquina, e não em seu sistema operacional, sendo este entendido apenas como um complemento barato, permitiram que o DOS, por estar associado ao nome IBM, e pela habilidade estratégica da Microsoft, com o tempo, se tornasse o padrão da indústria. Esqueceram-se de que, sem os sistemas operacionais, o computador era apenas uma caixa que ficava piscando suas luzes.

O lado pitoresco desta história foi que, tempos depois, descobriu-se que a Seattle havia copiado o Q-DOS da Digital Research, a partir de seu CP/M. A IBM ainda teve que indenizar a Digital em 800 mil dólares para não ser processada. Até hoje, nas versões do MS-DOS que comandam nossos computadores pessoais, por baixo das outras interfaces todas, são encontradas linhas de código escritas por Gary Kildall, fundador da Digital Research (ROHM, 2001).

Por essa época, os engenheiros da Xerox desenvolveram duas inovações para serem incorporadas aos microcomputadores: uma interface gráfica de tela que possuía botões virtuais que poderiam ser acionados por um cursor manual, que tinha sido chamado de 
mouse, que operava na interface. Por entenderem aquelas inovações quase como sendo um brinquedo, não compatível com os objetivos e a "seriedade" de sua empresa, os executivos da Xerox descartaram sua utilização, sequer "perdendo tempo" em patenteá-las (ROHM, 2001).

Quando teve conhecimento dessas novidades, Steve Jobs imediatamente procurou a Xerox que, sem maiores dificuldades, deu-lhe acesso àquelas tecnologias, que uma vez absorvidas, foram patenteadas pela Apple. Com a utilização dessa nova tecnologia foi possível eliminar seus concorrentes do segmento dos equipamentos domésticos com o Apple II. Em pouco tempo a Apple era a maior fabricante de computadores pessoais. Primeiro veio o II Plus. Depois o lle. Cada máquina era compatível com o desenho anterior; cada uma podia usar o mesmo software, e cada uma delas era desenhada para substituir sua antecessora. Além do fato de ser a única fabricante de computadores pessoais que não utilizava o sistema operacional de disco imposto pela IBM ao mercado, o MS-DOS.

A Microsoft, interessada em produzir aplicativos para o Maclntosh, que estava sendo desenvolvido pela Apple, recebeu três protótipos da máquina e de seu sistema operacional para auxiliar nas suas próprias pesquisas. Utilizando-se dos conceitos e métodos de engenharia reversa, os códigos foram abertos e copiados, permitindo que, em 1981 a Microsoft lançasse o Windows, atrelado ao seu MS-DOS.

Os demais concorrentes, aproveitando-se do fato de que a IBM abrira sua arquitetura anos antes, rapidamente começaram a fabricar os chamados PC-compatíveis, e, utilizando-se de componentes montados em países asiáticos, de preços muito baixos, em poucos anos, tornaram-se donos de mais de $80 \%$ do mercado de computadores, que pertencera quase todo à IBM. Essa estratégia de custos baixos e flexíveis, mostrou-se muito atraente para este tipo de indústria. O pouco peso e pequeno tamanho dos componentes possibilitavam grande alavancagem, pois permitiam sua fabricação em países de mão de obra barata. Essa estratégia vem sendo utilizada até nossos dias, hoje com altos níveis de sofisticação logística, dadas nossas atuais condições de comunicação e transporte.

Em 1987 a IBM lançou uma segunda geração de computadores pessoais - a linha PS, destinada a substituir a linha PC. O PS/2, de 32 bits, utilizava o sistema operacional OS/2, que foi apresentado como uma grande evolução tecnológica. Esse sistema foi desenvolvido em conjunto com a Microsoft, que, mostrando-se plenamente dedicada a desenvolver o OS/2, na realidade provocava atrasos em seu lançamento, enquanto, secretamente, empenhava-se ao máximo no seu próprio projeto, uma nova versão do Windows. Enquanto dizia para a IBM que tanto o DOS quanto o Windows estariam mortos após o lançamento do OS/2, dizia aos ISV (produtores independentes de softwares aplicativos) que continuassem trabalhando na plataforma Windows, pois a mesma iria passar por um fantástico up-grade em futuro bem próximo (ROHM, 2001). Essa situação acabou conduzindo as duas empresas a um impasse.

Em 1989, ambas declararam de forma oficial que tinham chegado a um acordo. 0 sistema OS/2 seria a solução de negócios para computadores mais poderosos, enquanto o Windows seria aplicado em computadores menores, do tipo pessoal ou para pequenos negócios. Todavia, ao mesmo tempo em que esse anúncio era feito, a IBM descobria que, de fato, seu sistema operacional tinha muitos defeitos, e, literalmente, não funcionava ( $R O H M$, 2001). Praticamente todos os engenheiros da empresa foram deslocados para consertar o produto, propositadamente deixado fora de mercado por Gates, com o intuito de facilitar a comercialização de seu Windows, sem as restrições de mercado que a IBM pretendia impor-lhe. Esse atraso custou a vida da nova linha PS da IBM (RAPP; COLLINS, 1994). 
Em 1987, Andrew Tanenbaum tinha anunciado o Minix, versão simplificada do Unix, para uso em desktops. Em 1988, finalmente, surgiu um concorrente poderoso para Microsoft. A Digital Research, que tinha tido o seu sistema operacional original copiado pela Seattle e posteriormente revendido à Microsoft, estava entrando no mercado com um novo produto, tecnicamente melhor que o MS-DOS, chamado DR-DOS.

Mesmo com um produto pior, a Microsoft enfrentou comercialmente a Digital e seu DRDOS-5 (ROHM, 2001). Já que a estrutura de seus programas funcionava "em camadas", tecnicamente seria possível que o usuário optasse pelo DR-DOS, que era melhor, para suportar a plataforma Windows, ainda única no mercado DOS, e isso Gates não poderia permitir, sob pena de, rapidamente ver surgirem novas plataformas concorrentes à sua. Aproveitando-se de que, naquele momento, por ter sido a primeira a ocupar o mercado, era a líder, a Microsoftutilizou-se de modo extremamente pesado da estratégia de fazer vendas casadas. Só levava o Windows o fabricante de PCs que comprasse também o seu DOS. Também alterou algumas linhas do código de sua plataforma, de modo a impedir que a mesma funcionasse adequadamente com o DR-DOS. Em quatro anos o DR-DOS morreu (ROHM, 2001).

Por essa época, o finlandês Linus Torvalds, estudante de Ciência da Computação na Universidade de Helsinque, interessou-se em criar um sistema operacional de código aberto a partir do uso do Minix, que possuía uma série de limitações técnicas e, além de tudo, era caro. A plataforma desenvolvida por Torvalds era poderosa e flexível o suficiente para superar os obstáculos do Minix, e mais, podia ser alterada livremente por qualquer pessoa interessada em melhorar ou adaptar o sistema operacional. Em agosto de 91 a primeira versão da nova plataforma foi distribuída pela Internet, tendo sido batizada por Torvalds como Linux - uma brincadeira que unia seu prenome Linus e Unix.
O fato de ter sido construído como um software livre interessou imediatamente à comunidade acadêmica, que passou a contribuir de modo consistente para o desenvolvimento da plataforma. O projeto GNU, idealizado por pesquisadores do Massachucetts Institute of Technology (MIT) em 1983, vinha trabalhando para obter um sistema operacional não proprietário e a opção pela compatibilidade com o Unix se deu em função da estabilidade da plataforma e pelo número de usuários que já utilizavam esse sistema operacional. Seus colaboradores, ao longo dos anos, desenvolveram uma série de componentes do sistema operacional, como editores de texto, programas de formatação e compiladores, etc., tudo compatível com Unix. Mas ainda faltava o núcleo do sistema, que por si só, não representa muita coisa quando se trata de um sistema operacional completo. Além do núcleo, uma série de funções adicionais básicas precisa ser desenvolvida. Como Torvalds disponibilizou o código-fonte do núcleo de seu sistema operacional, que emulava o Unix, e os pesquisadores tinham todos os seus aplicativos já desenvolvidos para rodar nesse mesmo sistema, a associação entre eles ocorreu naturalmente. Em 1991, nascia o GNU/Linux, modelo de sistema operacional completo, não proprietário, que, a partir de então vem sendo desenvolvido incessantemente.

Em sua vertiginosa evolução, os microcomputadores adquiriram tal poder de processamento que começaram a executar tarefas antes exclusivas dos grandes computadores. Essa tendência de mercado fez com que numerosas empresas, usuárias dos mainframe, transferissem o seu processamento para microcomputadores interligados em rede, a custos significativamente menores.

\section{A Internet: o momento tecnológico atual}

O chip revolucionou a administração dos negócios, a cultura e a sociedade dos povos. 
Se os mainframe da década de 50/70 refletiam uma postura centralizadora de uma geração que se deparava com uma guerra mundial e em seguida viveu a pressão da bipolarização das forças político-econômicas hegemônicas, à espera da bomba final, hoje, na era da Internet, a filosofia é totalmente descentralizada.

A Internet, nascida na "guerra fria", transformou-se na grande alavanca que remeteu os computadores pessoais para a espetacular presença em nossas vidas que os mesmos têm hoje em dia. Em 1995, o acesso aos microcomputadores era feito por programas como o Windows e o Mac/OS, bastante amigáveis, mas, para entrar na internet, o usuário ainda precisava digitar comandos complicados. Em resposta a essa necessidade do mercado, uma pequena empresa de software, a Netscape, lançava um programa de navegação para abrir páginas pela rede, que rapidamente alcançou a liderança em seu setor. Esse era o ponto central da questão: com o surgimento da rede, uma empresa altamente tecnológica, competente na utilização dos novos conceitos trazidos pela Internet, e rápida, poderia abalar e até destruir o monopólio da Microsoft. As páginas (da rede) estavam se tornando aplicativos, e a Netscape / Java estava usando o navegador para criar um "sistema operacional virtual".

A Microsoft sempre perseguiu uma estratégia de influência, através da criação de ligações tecnológicas entre seus monopólios estabelecidos e os novos mercados que estava prospectando. A utilização desses links tecnológicos, aliados ao monopólio do Windows, novamente entraram em cena, bem como sua já clássica utilização de ações de estratégia de posicionamento e formação de poder para negociar. A Microsoft lançou o Windows 95, já incorporando a ele o seu navegador Internet Explorer, que aparecia como um dos ícones de sua tela de abertura. Tecnicamente era possível substituir o navegador instalado, pelo da
Netscape, porém os fabricantes de PCs, em razão de imposição da Microsoft, estavam impedidos de vender o Windows sem o Explorer, o que, para o usuário que desejasse utilizar o navegador da concorrência, implicava em aumento de custos e tempo despendido para efetuar a troca. A comodidade do usuário fez 0 resto (ROHM, 2001).

Todavia, em paralelo à trajetória da Microsoft, desde o seu lançamento, de modo lento, mas progressivo, o Linux vem entrando no mundo corporativo, a partir da participação de empresas de software, o que não aconteceu por acaso. A princípio, o sistema operacional passou a fazer parte da infra-estrutura das empresas, solucionando pequenos problemas. Muitas vezes ele era utilizado por sugestão de técnicos que já conheciam o sistema operacional ou alguma das aplicações construídas em código livre e que optavam por utilizá-las em substituição a outra ferramenta proprietária. Com o passar do tempo, mais empresas passaram a utilizar o Linux, e isso acabou levando as software-houses a não apenas oferecerem suporte, mas, e principalmente, a prepararem versões especiais do sistema operacional.

Para que seja possível compreender a evolução do Linux no ambiente corporativo, torna-se necessário entender alguns aspectos importantes. O Linux trabalha na arquitetura Intel, a mesma que suporta o Windows, ao contrário do Unix, que utiliza servidores Risc. Vale a pena analisar números do mercado, considerando uma conjuntura mais ampla. No segundo trimestre de 2003, as vendas mundiais de servidores baseados na arquitetura Intel atingiram US $\$ 4,46$ bilhões, superando as de servidores Risc, que foram de US\$ 4,3 bilhões. Segundo a International Data Corp (IDC), no período analisado, as vendas dos servidores Intel aumentaram 10,7\% em relação ao ano anterior, enquanto as vendas de servidores Risc caíram $5,2 \%$. Mas esse cenário não mostra um crescimento do Windows? A própria IDC explica. 
Em 2002, a venda de sistemas operacionais para servidores, que totalizou 5,7 milhões de licenças para uma receita de US $\$ 7,8$ bilhões, foi 5,1\% inferior à do ano anterior. Se houve aumento no número de servidores comercializados na plataforma Intel, com respectiva redução nas vendas de servidores Risc, e declínio na comercialização de licenças de sistemas operacionais, a equação só fecha com uma maior penetração do sistema operacional de código livre (COMPUTER WORLD, 2004).

Os maiores fabricantes de hardware e desenvolvedores de software investem, para tornar seus produtos compatíveis com o Linux, como a PeopleSoft, Siebel, BEA Systems, Oracle e SAP, que já portaram seus produtos para o Linux. Elas são companhias de grande porte e de representatividade no cenário internacional do mercado de tecnologia. Há pouco mais de três anos, Hewlett-Packard, IBM, Computer Associates, Intel e NEC criaram o Open Sources Development Labs, que coloca à disposição de desenvolvedores Linux do mundo todo o que existe de mais avançado em termos de equipamentos de informática e ambientes de teste, nos Estados Unidos e no Japão. Atualmente, esse consórcio conta com o apoio de quase 30 empresas e a colaboração, em tempo integral, de Linus Torvalds. Ele também será responsável pela coordenação do desenvolvimento de novas versões do núcleo do Linux.

A HP e a NEC, adaptaram seus servidores para rodar outros sistemas operacionais, incluindo Linux, e já começaram a colher frutos dessa estratégia. De acordo com a IDC, a HP é líder mundial no fornecimento de servidores Linux e vem trabalhando efetivamente para prover soluções baseadas em código aberto, que estejam diretamente relacionadas ao negócio das corporações, e não apenas à infra-estrutura de rede. É o caso da aliança entre a HP e a Oracle para banco de dados. A CA, por sua vez, adaptou todo o seu portfólio para o ambiente
Linux, assegurando melhores condições de integração, eficiência e, principalmente, segurança à plataforma.

Outra empresa que tem muito interesse na adoção do Linux em grande escala é a Intel, que já domina o mercado dos processadores de ambiente Windows, e só tem a ganhar com a chegada da plataforma aberta e sua ampla aceitação no mercado corporativo.

Esse mercado passa a contar com um ambiente robusto, equiparável em termos de estabilidade e eficiência com a plataforma Unix, em máquinas bem mais acessíveis em termos de custos, baseadas em Intel.

A partir da segunda metade dos anos 90 , com a popularização da rede mundial, a indústria de informática apostou na redução de custos, na miniaturização e na portabilidade das máquinas. A Internet mudou o marketing, o atendimento de clientes, a forma de fazer negócios, o aprendizado. O número de possíveis aplicações da Internet é praticamente infinito.

$\mathrm{Na}$ virada do milênio, toda a indústria de alta tecnologia sofreu com o estouro da bolha artificial de preços de suas ações, que despencaram nas Bolsas de New York e do mundo. Hoje em dia, alguns anos depois, encontramos a HP, depois de comprar a Compaq, como o maior fabricante mundial de PCs, seguida de perto pela Dell. (no quarto trimestre de 2003, a HP teve uma participação global de 16,9\% contra 16,3\% da Dell, segundo a International Data Corporation (IDC). Hoje se calcula que 400 milhões de pessoas acessem a Internet por algum tipo de computador. Segundo uma estimativa da IBM, são 500 milhões os PCs espalhados pelo mundo (DELL; BARRET, 2004).

\section{O N CLUS Ã O}

O Linux é a maior e mais séria ameaça à Microsoft desde o surgimento da Internet no meio 
dos anos 90. A imagem alegórica que a já declarada disputa entre os dois sistemas traz à nossa mente, é aquela onde a Microsoft se assemelha a um velho jogador de futebol, logo após o auge da carreira, famoso, respeitado e ainda muito útil para o time, mas já sem a explosão muscular que a profissão exige. Enquanto o Linux é o garoto de 17 anos, craque, ainda inexperiente, que começa a mostrar os primeiros toques geniais na bola e a ganhar os jogos para o time, com a arrogância própria dos que conhecem seu valor. A torcida já começa a achar que ele é o melhor de todos, que o antigo ídolo já pode "pendurar a chuteira". O Linux pode fazer uma carreira fantástica, até maior que a do velho jogador, mas, apesar do que acha a torcida, às vezes até manifestado de forma feroz, pode também terminar jogando na várzea.

Pela primeira vez a Microsoft se defronta com um competidor que não se amedronta com seu parque instalado, nem com suas antigas estratégias de preempção ou de dumping, nem mesmo com seu poderio tecnológico. É um adversário estranho, que não tem escritório com executivos em nenhum lugar, aliás, nem tem executivos. Nem tem nada. É multifacetado. Vive nas máquinas que rodam Intel, evolui na cabeça de mais de 100 mil desenvolvedores pelo mundo, e alimenta-se da vontade de derrotar Gates.

O Windows custa o valor de seu licenciamento para o usuário. O Linux não tem licença, não é proprietário. Em tese, não custa nada. $\mathrm{Na}$ realidade, existe o Total Cost of Ownership (TCO) - custo total de propriedade), cuja análise deve ser vista como uma equação em que as variáveis e os seus coeficientes determinam o resultado, não existindo regulamentação ou normalização internacional, razão pela que é sempre subjetivo determinar o que entra ou não na equação, o que permite que a Microsoft divulgue análises teóricas, onde 0 TCO do Linux seria maior que o do Windows.

Essa guerra de informações não atinge os executivos de TI, que sabem que o Linux é uma realidade, que no longo prazo é mais barato que sistemas proprietários, e que, estrategicamente, permite a independência frente ao monopólio. Também sabem que, de fato, o Linux não é um sistema operacional completamente maduro, que possa ser usado em sistemas de missão crítica, mas é estável e continuamente em desenvolvimento. Já são muitas as empresas, pelo mundo todo, que utilizam o software livre em todas as suas soluções. O Gartner Institute, em pesquisa divulgada no último trimestre de 2003 (PC WORLD EXTRA, 2004), afirma que o Linux continua ganhando impulso, à medida que vão sendo derrubados os argumentos contra sua estabilidade e desempenho.

Os especialistas do Gartner estimam que até 2008 o Linux já terá alcançado a mesma confiabilidade e os mesmos níveis de gerenciamento e disponibilidade assegurados pelo mainframe e pelo Unix - e mais, na plataforma Intel, muito mais acessível em termos econômicos do que a Risc. Segundo a entidade, em cinco anos, pelo menos $60 \%$ das corporações (empresas com mais de 500 funcionários) terão migrado mais de dois terços das aplicações baseadas em Unix para Linux, estimuladas, principalmente, pelo interesse das grandes empresas de software em desenvolver aplicações compatíveis com o sistema operacional de código livre.

Qualquer que seja o resultado desta disputa, a primeira vítima já é conhecida. Se as projeções sobre o desenvolvimento tecnológico do Linux estiverem corretas, em cinco anos ele terá a mesma capacidade que o Unix tem hoje de operar servidores de rede e de missão crítica. Se hoje ele já vem tomando mercado do Unix, quando estiverem operacionalmente equalizados, então, a tendência será para uma existência apenas residual do Unix.

E aí, provavelmente, quem viver verá o Armagedon. Um Linux poderoso, bem posiciona- 
do após ter dominado o mundo mainframe, que estará rapidamente caminhando para a barata arquitetura Intel, em excepcionais condições para avançar sobre a plataforma baixa, contra o monopólio e seus advogados, impondo a vitória do código livre, sob os aplausos comovidos da IBM, da Novell, da Java, da Sun, e de muitas outras empresas que não sobreviveram às disputas com a Microsoft para apreciar o momento.

\section{RE FER Ê N CIAS}

COMPUTERWORLD. Preso ao software livre, São Paulo, n.408, Mai. 2004.

DELL, M.; BARRET, C. Agente da mudança. Information Week Brasil, v.5, n.114, p.28-32, 2004.

PC WORLD EXTRA LINUX. São Paulo. Edição Especial 2, 2004.
Ou não? Ou esse dia nunca chegará? Conseguirá a Microsoft encontrar uma saída estratégica para a situação que vive hoje? Ela possui tudo o que precisa para se reposicionar nesse confronto. Tem tecnologia, muitos recursos e, acima de tudo, a incrível tenacidade de seu fundador em vencer todas as disputas nas quais foi colocado, sempre derrotando todos os adversários que ousaram desafiar o império. Ave, Gates, primeiro e único.

RAPP, S.; COLLINS, T.L. Maxi-Marketing: os vencedores. São Paulo: Makron Books, 1994.

RIES, AL; TROUT, Jack. Marketing de guerra. São Paulo: McGraw-Hill, 1989.

ROHM, Wendy G. O Caso Microsoft. São Paulo: Geração Editorial, 2001. 